\title{
LAS INSCRIPCIONES CORPORALES DEL INDIO: CANIBALISMO Y DESNUDEZ EN PEDRO CIEZA DE LEÓN
}

\author{
Jorge Chen Sham
}

\begin{abstract}
RESUMEN
Tanto los rituales del arreglo corporal como los de una antropofagia ritual, que pasan desapercibidos al ojo eurocéntrico por cuanto este no posee la capacidad de observar en ellos ni prácticas de etiqueta ni tampoco usos de un simbolismo colectivo, cobran valor dentro de unas inscripciones corporales del cuerpo. Reconfigurarlas dentro de un entorno en la que noción de cuerpo se gramaticaliza hace que el canibalismo y la desnudez, los dos tópicos para subvalorar al sujeto indígena, se revisen. Con esta finalidad se analiza la crónica de Pedro de Cieza de León, quien escribió la Crónica del Perú, el señorío de los Incas (Sevilla 1553).

Palabras clave: Pedro de Cieza de León, Crónica del Perú, crónicas coloniales, cuerpo del indígena, canibalismo, desnudez.
\end{abstract}

\begin{abstract}
Although rituals concerning the decoration of the body as a cannibalistic ritual might go unnoticed by the Eurocentric viewer because they do not have the capacity to observe in them neither practices of etiquette nor uses of a collective symbolism, they are valuable when you look in detail at the inscriptions of the body. Reconfiguring them within an environment in which a notion transforms itself into an idea that makes sense of cannibalism and nakedness, two topics, which are understudied indigenous subjects, are reviewed. To this end we analyze of the chronicle of Pedro de Cieza de Leon, who wrote the Chronicle of Peru, the dominion of the Incas (Sevilla 1553).

Keywords: Pedro de Cieza de Leon, Chronicle of Peru, colonial chronicles, the indigenous body, cannibalism, nudity.
\end{abstract}

Partimos de la siguiente pregunta: ¿cómo hacer hablar las crónicas coloniales, teniendo en cuenta su punto de vista eurocéntrico, al servicio de la propaganda fidei de la Monarquía española? Se trata de la toma de conciencia de que su discurso ha servido para elaborar simbólicamente representaciones del sujeto indígena con su entorno social y con las instituciones a las que ha servido y a las cuales se ampara (Moraña 1998: 243). Lo anterior ha

Dr. Jorge Chen Sham. Profesor catedrático de la Escuela de Filología, Lingüística y Literatura de la Universidad de Costa Rica. Miembro correspondiente de la Academia Nicaragüense de la Lengua y colaborador de la Academia Norteamericana de la Lengua Española.

Correo electrónico: jorgechsh@yahoo.com

Recepción: 22- 10- 2012

Aceptación: 27- 11- 2012 
conducido a que el discurso académico vea con suspicacia, sobre todo las crónicas coloniales ${ }^{1}$, en tanto portadoras de una visión que materializa, ya sea exclusiones socioculturales a lo largo de la Conquista, ya sea como medios de expresión de la propaganda apologética de España. En este sentido, ¿tiene alguna relevancia lo que podamos extraer de estas crónicas, cuando, a partir de las ciencias sociales y de la arqueología foucaldiana del discurso se ponen en duda el dictum y su palabra? Aun más, actualmente se cuestiona el grado de exactitud y de fiabilidad histórica que debemos otorgarle a su carácter de información, sobre todo, etnográfica, cuando "los imperios colonizadores [siempre] han pretendido imponer modos de comportamiento sobre la población colonizada" (Gonzalbo 2000: 7).

Sin embargo, y a pesar de su visión hegemónica y monolítica, las crónicas coloniales siguen constituyendo uno de los corpus más sólidos para aprehender la realidad colonial americana; lo que debe hacerse es realizar una lectura diferencial y distinta de ellas. En la óptica de la curiosidad y de la novedad, propias del saber letrado del Antiguo Régimen, las crónicas describen aspectos de las sociedades indígenas en el orden civil y natural en una jerarquía y sistema clasificatorios que establecen las bases del nuevo orden, pues la realidad americana aparecía como un vasto mundo por definir, ordenar y clasificar (Coello de la Rosa 2005: 55). Como plantea José Antonio Mazzotti, los patrones eurocéntricos harán que los cronistas vean sus costumbres y las religiones desde la censura de una ortodoxia cristiana o desde el apelativo del buen salvaje. La mirada exotópica y, por lo tanto, extraña y exclusivista se impone para fines "del control directo de la Corona y de la Iglesia en la empresa conquistadora" (Mazzotti 1998: 85), esto no se puede negar de ninguna manera. Hay que estar consciente de que unos intereses políticos u otras justificaciones moralista-religiosas intervienen en sus valoraciones de los cronistas, al punto de discriminar y de establecer criterios de valoración con implicaciones éticas o políticas (Gonzalbo 2000: 9).

Estas implicaciones convergen en el plano del sometimiento y conquista del indio. En cuanto a las religiones indígenas, se justifica tanto la intervención/expansión de la civilización cristiana como su percepción de su minoría de edad (pafraseando a Michel Foucault) ${ }^{3}$ en el estado de degeneración moral y de minusvalía espiritual de sus ritos y supersticiones. Al relacionarlas con el demonio, esta percepción de inferioridad y de supremacía se irá haciendo más ostensible en la tesis de la estrecha relación entre idolatría y demonio, por un lado, y, por otro, la oposición entre la acción de Dios frente a los actos del diabólico. Como plantea Alexandre Coello de la Rosa para el último tercio del siglo XVI:

\footnotetext{
La maquinaria tridentina se volvió hacia el Nuevo Mundo como resultado de un sentimiento de ortodoxia religiosa contra los pueblos paganos, fomentando un discurso beligerante que dio lugar a una nueva imagen del Diablo, mucho más soberbio y vengativo que nunca. El resultado de sus malas actuaciones que no podía ser otro que la introducción de la "fealdad" de los ídolos en el imaginario de los indios, así como la aparición de tratados idolátricos y de indios idólatras. (2005: 56)
}

Por operación metonímica, esta fealdad de lo extraño y de lo que no es asimilable (Cros 1993: 45) desde el punto de vista religiosa, se desplazará a la representación de su cuerpo, de su asimilación y subordinación dentro de un mismo proceso que hace de la diferencia la expresión de su inferioridad, como lo observa en José de Acosta en su Historia natural y moral de las Indias (Sevilla 1590), cuando describir comportamientos diferentes y reformular la sociedad indígena a través de la óptica eurocéntrica, se hagan desde concepción de la ciudad de Dios, ordenada y jerárquica; dice al respecto Coello de la Rosa: "A diferencia de los primeros cronistas españoles, cuyas primeras descripciones habían encasillado a todos los indios dentro de una etiqueta simple y genérica, la filosofía tomista dio lugar a un orden histórico -natural y 
moral- coherente con el nuevo orden imperial. Aquellos pueblos -bárbaros- cuyas costumbres y religión iban en contra del catolicismo tridentino debían ser evangelizados de acuerdo con un orden moral hegemónico" (Coello 2005: 55-56).

Pero lo que es claro ya en esta etapa posterior, la del esplendor de las crónicas, no lo es en los primeros cronistas, los primitivos, de la etapa de descubrimiento, conquista, cuya representación del indio no se ajusta a estas valoraciones exageradas y tan deformadas. Ya Karl Kohut ha demostrado la importancia que, en estas crónicas de la etapa primitiva, posee la historia de un soldado-cronista, pues "destaca su experiencia personal (lo visto y lo vivido)" (2009: 163), respaldándose en lo que plantea Fernández de Oviedo para sí mismo, en donde primordial es que se escriba sin adorno, sin circunloquios, haciendo protestas de su poca cultura, de un estilo llano que subraya el tópico de la falsa modestia. Pero que, al fin y al cabo, manifiesta la triple tarea la del cronista:

\footnotetext{
La misma [conciencia] es clara en las tareas específicas que se le asignan al nombrarlo cronista de Indias, pues como tal debe: (1) "escribir las cosas que han sucedido y sucediesen en las nuestras Indias, desde el tiempo que así se descubrieron"; (2) describir las "propiedades y extrañezas de cada isla y tierra"; (3) explicar "las condiciones de los moradores y animales dellas". Es decir, el cronista debía cubrir las tareas de un historiador, un geógrafo y un etnólogo. (Kohut 2009: 164)
}

Dos etapas del trabajo se ponderan en la escritura: ver y oír, para luego escribir. Para ello, seguiremos las trazas de la retórica del cuerpo. A partir de los diccionarios coloniales, Alexandre Surallés (2010: 65) ha planteado para la región mesoamericana una noción sustancialista del cuerpo, relacionada con su materia, la carne, y sus partes, y "los seres que las detentan", mientras que para el Cono Sur encuentra, más bien, una noción formalista en la que el cuerpo es sobre todo volumen, pues "evita a toda costa una relación entre cuerpo humano y carne, y propone en cambio una traducción de cuerpo haciendo referencia al espacio que ocupa, es decir, su forma" (Surallés 2010: 80). Dicho de otra manera, en tanto forma que contiene o es contenida, el cuerpo "es forma de la materia y sólo en el caso humano esta última sería la carne" (Surallés 2010: 80). El cuerpo humano debe revisarse y limitarse en sus contornos por su materia y por su forma; exige una gramática de los cuerpos. Con esta finalidad, nos ubicaremos en los rasgos corporales del indio a través de la adquisición de técnicas, costumbres, usos, ritos; se trata de otorgarle un valor etnográfico al discurso de las crónicas coloniales; pero también es proporcionarle una expresión humana ligada a la teatralidad de los sentimientos y afectos (Münzel 2010: 117). Así, aprehender marcas socio-culturales del cuerpo es posible si se rastrea en la superficie del discurso cronístico, de manera que la producción textual explicita ciertas huellas y rastros de sentido sobre el cuerpo de la crónica, al mismo tiempo que lo hace sobre la piel del indio, y los sentimientos que se despiertan. Dicho de otra manera, una cultura modela el cuerpo y deja sus marcas en su carne por medio de recortes, deformaciones o agregados, esto es lo que plantea David Le Breton como inscripciones corporales, cuyo valor se correlaciona con la identidad o la pertenencia social, la inclusión en grupos, la identificación étnica, etc.:

Estas inscripciones corporales llenan funciones diferentes según las sociedades. En tanto instrumentos de seducción, suelen ser un modo ritual de filiación y de separación. Integran simbólicamente al hombre dentro de la comunidad, del clan, y lo separan de los hombres de otras comunidades o de otros clanes al mismo tiempo que de la manera que lo rodea. Humanizan al hombre al ponerlo socialmente en el mundo [...]. Duplican de un modo visible por todos el estatus social o más específicamente matrimonial. A la manera de una memoria orgánica, pueden trazar el lugar de la persona en el linaje de los antepasados. Recuerdan los valores de la sociedad y el lugar legítimo de cada uno en la estructura social. (Le Breton 2002: 62-63) 
Las marcas en los cuerpos son innumerables y nuestro procedimiento será leerlas en las descripciones que hacen las crónicas, mediante los dos rasgos tópicos que ya marcan esa inserción del indio en las crónicas: su canibalismo y desnudez. Tomaré el caso de Pedro de Cieza de León, quien escribió la Crónica del Perú, el señorío de los Incas (Sevilla 1553); fue uno de esos conquistadores-soldados que estuvieron en el campo de observación y de batalla y, antes de partir hacia el Perú, estuvo en lo que fue parte del Virreinato de Nueva Granada, más exactamente en la región del Valle de Cauca, a principios de 1539, cuando se dirige a la villa de Ancerma (Umbra) y sus alrededores. Lo primero que le llama la atención es que sean "belicosos" y que tal característica la asocie Cieza al hecho de que sean caníbales, como lo describe en el Capítulo XV; veamos:

\footnotetext{
Cuando van a la guerra [se refiere a los caciques y guerreros], con agudos cuchillos de pedernal o de unos juncos, o de cortezas o cáscaras de cañas, que también los hacen de ellas bien agudos cortan las cabezas a los que prenden. Y a otros dan muertes temerosas, cortándoles algunos miembros, según su costumbre, a los cuales comen luego, poniendo las cabezas (como he dicho) en lo alto de las cañas. (Cieza de León 2005: 48)
}

La fiereza y la belicosidad se contrapone a la domesticidad de los indios; estos son rasgos que el propio Cieza expone dos capítulos antes, cuando intenta explicar las diferencias entre los indios de la provincia de Popayán y los del Perú; los primeros son indómitos, mientras que los segundos son pacíficos (2005: 44). En esa misma línea, en la cita que analizamos, la bravura y fuerza se demuestra en las artes de la guerra, que solamente puede ser la traducción física de un comportamiento extraordinario: sus armas punzo-cortantes y bien afiladas reflejan su animosidad, al mismo tiempo que manifiestan sus demandas biológico-afectivas que se ciernen sobre los contrarios, en dos acciones: los decapitan guardando sus cabezas ostensiblemente o los destazan para ingerirlos. A Cieza se le escapa la interpretación de lo que describe; para plantearlo en términos etnográficos, no lo puede poner en su marco cultural de origen. Sin embargo, no hay aquí tampoco sanciones ni juicios contundentes, como en otros cronistas a los que tales actos de canibalismo los hubieran horrorizado, al punto de que los hubieran condenado como acciones demoniacas o de crueldad barbárica. Es más, cuenta Cieza un capítulo más adelante, que ellos mismos comieron carne humana en un momento de necesidad apremiante:

\footnotetext{
Porque entiendan los trabajos que se pasan en los descubrimientos, los que esto leyeren, quiero contar lo que aconteció en este pueblo, al tiempo que entramos en él con el licenciado Juan de Vadillo, y es que como tenían alzados los mantenimientos en algunas partes no hallábamos maíz, ni otra cosa que comer, y carne había más de un año que no la comíamos, si no era de los caballos que se morían, o de algunos perros, ni aun sal no teníamos, tanta era la miseria que pasábamos. Y saliendo veinte y cinco o treinta soldados, fueron a ranchear o por decirlo más claro a robar lo que pudiesen hallar, y [...] hallaron una olla grande llena de carne cocida, y tanta hambre llevaban, que no miraron en más de comer [...], mas ya que estaban bien hartos, un Cristiano sacó de la olla una mano con sus dedos y uñas, sin lo cual vieron luego pedazos de pies de dos o tres cuartos de hombre que en ella estaban. Lo cual visto por los españoles que allí se hallaron, les pesó de haber comido aquella vianda dándoles grande asco de ver los dedos y manos, mas a la fin se pasó, y volvieron hartos al real, de donde primero habían salido muertos de hambre. (Cieza de León 2005: 51-52)
}

La cita es extremadamente larga, pero no he podido cortarla porque expone Cieza en primer lugar la excusatio propter imfirmatem, es decir, justifica las razones por las cuales en este caso concreto, hayan violado una de las leyes que marca esa transición entre la animalidad (léase bestialidad en la óptica eurocéntrica) y la humanidad. En ese sentido, el sustantivo con el que se asocia la empresa de la conquista, los "trabajos", no es inocente en este contexto en el que remite a sufrimientos (Egido 2004: 18-19), de manera que Cieza 
apela a la comprensión de sus lectores, si ha revelado un secreto y lo confiesa públicamente. La insistencia en el hambre y en la necesidad de satisfacer esta necesidad biológica hace que los soldados, obnubilados y ávidos por comer, no hayan reconocido ni las manos ni los pies como partes del cuerpo humano, hasta que se hubieran saciado. Si aquí el fin justifica los medios, Cieza invita a la comprensión ideológica en un momento en que vuelve a insistir en el canibalismo de los indios de Umbra. Volviendo ahora a esa representación que nos interesa, los cuerpos humanos desmembrados en la guerra o en las ceremonias que vienen aparejadas a ella no causan, en Cieza, ni repulsión ni horror; su descripción se encuentra inserta en ritos asociados con la comunión y el poder simbólico de los cuerpos de los enemigos o contrarios. La actitud occidental y eurocéntrica no suele en la mayoría de las veces comprender "el poder de los sistemas simbólicos que proporcionan contorno y sentido a la vida colectiva de las comunidades humanas alejadas de nuestros modos de existencia" (Le Breton 2002: 61) y, en este caso, la ingestión de la carne humana en ritos de valor guerrero son propios de una comunión simbólica y cultural. Queda claro que se ubica dentro de un conjunto de sortilegios de protección como pueden ser el empalizamiento de cabezas, o la transmisión de poderes simbólicos de los cuerpos de los adversarios dentro de una ingestión propiciatoria, cuya emanación ejerce una importante influencia en las relaciones sociales, porque Cieza encuentra en los grupos indígenas de la Nueva Granada la misma práctica de canibalismo. Tiene razón Mark Münzel en disociar la violencia de la desmembración de los cuerpos y la práctica del canibalismo de los sentimientos individuales y de los afectos que puedan venir aparejados a ellos, pues “'[i]ra' y 'furia' [agregaríamos nosotros, en estos rituales sociales] aquí no son vistas como sentimientos en el fondo del corazón, sino como expresiones de una actitud pública a veces violenta" (2010: 117-118) en el marco de la integración/afirmación grupal. Así, a diferencia de lo que hacen los españoles, cuya exacerbación de las necesidades de alimento los llevarían a comer carne humana, la antropofagia tiene una función dentro de un teatro social cuyas ceremonias refuerzan la identidad colectiva.

El otro ejemplo que deseamos abordar se refiere al tópico de la desnudez y la vestimenta. Por cierto los indios desnudos siempre sorprendieron al conquistador español. En el Capítulo XVI, Cieza presenta otro de los pueblos de la región, los de Zopia; al describirlos aclara lo siguiente:

\footnotetext{
Los hombres andan desnudos, y los principales y señores se cubren con una manta larga, y traen por la cintura maures como los demás. Las mujeres andan vestidas como digo, traen los cabellos muy peinados, y en los cuellos muy lindos collares de piezas ricas de oro, y en las orejas zarcillos, las ventanas de las narices se abren para poner unas como peloticas de oro fino, algunas de estas son pequeñas y otras mayores. Tenían muchos vasos de oro los señores con que bebían, y mantas, así para ellos como para sus mujeres chapadas de unas piezas de oro hechas a manera redonda, y otras como estrellitas, y otras joyas de muchas maneras tenían de este metal. (Cieza de León 2005: 52-53)
}

Desde el punto de vista del cuerpo se marca la desnudez/la vestimenta. Si en los indígenas caribes vistos por Colón, por ejemplo, la desnudez será la marca de su inferioridad y su escaso desarrollo, la vestimenta recubre del orden social, y observamos que su diferencia estratifica la descripción de Cieza de León. La "manta larga" y los "maures", a manera de cinturón para ceñir la manta, dan aquí un aire de sofisticación y de elegancia a los "principales y señores". Ahora bien, observemos que las "mujeres andan vestidas" y se aprecia en ellas unos códigos estéticos que se distinguen por "los cabellos muy peinados", signo de orden y de limpieza, y los adornos que se ponen; collares y piercings se distinguen aquí como marcas de elegancia y de belleza. En el caso de los indígenas de Colombia, Cieza de León se sorprende 
por la orfebrería y los utensilios en oro de estos pueblos; en concreto, señala el uso de "copas" y "mantas" enjabelgadas de adornos en oro, los cuales sorprenden al español; pero no puede ponerlos dentro de un contexto de ritos y comportamientos grupales, es decir, si estos se usaban en ceremomias de culto religioso, festejos o celebraciones; es decir, no indica en qué situaciones y para qué se empleaban.

Hagamos un contraste con otra descripción que Cieza de León hace de los indios de Urabá, en las cercanías del Río Darién, en lo que en aquel momento era parte de la Gobernación de Tierra Firme y correspondía a la región del atlántico colombiano. La desnudez es una conducta que identifica al sexo masculino, mientras de nuevo las mujeres van vestidas de dos piezas:

\footnotetext{
Las mujeres andan vestidas con unas mantas que les cubren de las tetas a los pies. Y de los pechos arriba tienen otro manta con que se cubren. Précianse de hermosas, y así andan siempre peinadas y galanas a su costumbre. Los hombres andan desnudos y descalzos sin traer en sus cuerpos otra cobertura ni vestidura que la que les dio natura. En las partes deshonestas traían atados con unos hilos unos caracoles de hueso o de muy fino oro, que pesaban algunos que yo vi a cuarenta y a cincuenta pesos cada uno y algunos más, y poco menos. (Cieza de León 2005: 31)
}

El cabello arreglado y recogido, la belleza de la que hacen alarde, es una constante para describir la modelización del cuerpo femenino, sometido a la regulación social de cubrirse. Y para el hombre, el cronista pone toda su atención en la desnudez total de su cuerpo y, en este sentido, la mirada se dirige hacia las partes pudendas, que se exhiben con decoraciones de orfebrería que acentúan los signos masculinos de la potencia sexual y viril. Estas imágenes del cuerpo masculino convergen alrededor de lo ostentatorio y pecuniario, cuando Cieza se sirve del valor y tamaño de pieza moneda para describir sus impresiones, en esta asimilación entre el asombro por la desnudez, los colgantes masculinos, y el tamaño de los órganos, todo lo cual resulta valioso en relación con el trabajo del hueso o la orfebrería de oro; estamos como dice la expresión ante unas "verdaderas joyas de familia". Las formas refinadas de la cultura, a la que los usos de aseo, de embellecimiento, o de decoración corporales pertenecen, son más bien ponderadas para las tres sociedades de la América precolombina más significativas a causa del tipo de desarrollo socio-político (inca, azteca, maya), pues gracias a su refinamiento y al desarrollo de sus sistemas de gobierno, leyes e instituciones, estaban en la cúspide de las sociedades precolombinas, aunque fueran idólatras y no tuvieran una escritura alfabética (Coello 2005: 63).

Lo que sí queda claro es que hay rituales de aseo personal y de arreglo del cuerpo que pasan desapercibidos al ojo eurocéntrico, el cual no posee la capacidad de observar en ellas ni prácticas de etiqueta (que serán propias de las sociedades civilizadas y refinadas), ni tampoco usos de arreglo corporal y belleza (menos cuando el cuerpo indígena será catalogado de feo, desarreglado, desproporcionado). Las inscripciones corporales permiten, entonces, reconfigurarlas en un entorno en que la noción de cuerpo se gramaticaliza y toma forma hablando en los sujetos y en las sociedades en las que se insertan. Gustavo Verdesio asegura que las sociedades indígenas han dejado sus huellas indelebles en un territorio representado a sus ojos como espacio habitado y ya inscrito por sus cuerpos. Los accidentes orográficos, la fauna y flora, la geografía, han sido nombrados y utilizados con anterioridad al descubrimiento español $\mathrm{y}$, de este modo, moldeados por los grupos indígenas que precedieron a los conquistadores/ cronistas (Verdesio 1999: 60); han dejado en este territorio sus rastros, es decir, su memoria histórica en vestigios, monumentos y códices; pero también lo han realizado con sus cuerpos 
que afloran en sus vestigios: los arqueológicos y los escriturales. Por lo anterior, si hoy se diversifica el uso de otras fuentes documentales y de materiales etnográficos provenientes de asentamientos arqueológicos, vestimenta, orfebrería y cerámica, urnas funerarias, estelas conmemorativas, inscripciones epigráficas, petrogríficos, tradición oral, etc., también el cuerpo indígena emerge como una evidencia material más allá del lugar en donde las ciencias sociales han investigado. Resta a quienes trabajan las crónicas coloniales restituir la evidencia escritural, cuyas huellas debemos releer a partir de lo que explícita/implícitamente escribieron los cronistas de Indias.

\section{Notas}

1. Utilizo este término para englobar la serie "cartas, crónicas, relaciones" (que hace necesariamente referencia al título de un trabajo de Walter Mignolo), aunque la heterogeneidad discursiva y la polivalencia pragmática obliguen a diferenciarlas (1982: 58-61).

2. En ese texto clave “QQué es la ilustración?”, indica lo siguiente: “Kant indica inmediatamente que esta «salida» que caracteriza la Aufklärung es un proceso que nos saca del estado de «minoría de edad»y por «minoría de edad» entiende cierto estado de nuestra voluntad que nos hace aceptar la autoridad de algún otro para conducirnos en los dominios en los que es conveniente hacer uso de la razón. Kant da tres ejemplos: estamos en estado de minoría de edad cuando un libro reemplaza nuestro entendimiento, cuando un director espiritual ocupa el lugar de nuestra conciencia, cuando un médico decide en vez de nosotros sobre nuestro regimen (señalemos de paso que se reconoce fácilmente el registro de tres críticas, aunque el texto no lo diga explícitamente). En todo caso, la Aufklärung se define por la modificación de la relación preexistente entre la voluntad, la autoridad y el uso de la razón" (1999: 338339, las cursivas son del texto). El discurso del otro americano desembocará en esta minoría de edad del indígena.

\section{Bibliografía}

Cieza de León, Pedro de. 2005. Crónica del Perú, El señorío de los incas (Edición de Franklin Pease). Caracas: Fundación Biblioteca Ayacucho.

Coello de la Rosa, Alexandre. 2005. "Más allá del Incario: Imperialismo e historia en José de Acosta, SJ (1540-1600)”. Colonial Latin American Review. 14 (1): 55-81.

Cros, Edmond. 1993. "Le semblable et l'altérité': structuration de l'instance discursive du Nouveau Monde". L'«indien», instance discursive (Actes du Colloque de Montréal, 1991). Candiac: Les Éditions Balzac.

Egido, Aurora. 2004. “Los trabajos en El Persiles”. En: Villar, 17-66.

Foucault, Michel. 1999. “QQué es la Ilustración?”. Estética, ética y hermenéutica. Obras esenciales. Volumen III. Barcelona: Paidós Ibérica.

Gonzalbo Aizpuru, Pilar. 2000.“La familia novohispana y la ruptura de los modelos”. Colonial Latin American Review. 9 (1): 7-19.

Gutiérrez Estévez, Manuel y Pedro Pitarch. 2010. Retóricas del cuerpo amerindio. Madrid/ Frankfurt: Iberoamericana/Vervuert.

Kohut, Karl. 2009. “Las primeras crónicas de Indias y la teoría historiográfica”. Colonial Latin American Review. 18 (2): 153-87.

Le Breton, Daniel. 2002. La sociología del cuerpo. Buenos Aires: Nueva Visión. 
Madrigal, Íñigo (Ed.). 1982. Historia de la literatura hispanoamericana. Época colonial. Madrid: Cátedra.

Mazzotti, José Antonio. 1998."Indigenismos de ayer: prototipos perdurables del discurso criollo". En: Moraña, 77-101.

Mignolo, Walter. 1982. “Cartas, crónicas y relaciones del descubrimiento y la conquista”. En: Madrigal, 57-116.

Moraña, Mabel (Ed.). 1998. Indigenismo hacia el fin de milenio: Homenaje a Antonio CornejoPolar. Pittsburgh: Instituto Internacional de Literatura Iberoamericana.

Münzel, Mark. 2010. “Antropofagia y sentimientos. Venganza y cariño en el cuerpo devorado". En: Gutiérrez y Pitarch, 117-152.

Surrallés, Alexandre. 2010. "La retórica de traducir “cuerpo"”. En: Gutiérrez y Pitarch, 57-86.

Villar Lecumberri, Alicia (Ed.). 2004. Peregrinamente peregrinos: Actas del V Congreso Internacional de la Asociación de Cervantistas. Lisboa, 1/5 de septiembre de 2003. Asociación de Cervantistas. 